\title{
Perceptions of Male Nurses about Nursing Profession
}

\author{
Muslim Shah ${ }^{1 *}$, Yasmin Parpio ${ }^{2}$, Zuhaid ${ }^{3}$ and Aurang Zeb ${ }^{4}$ \\ ${ }^{1}$ Rehman College of Nursing, Rehman Medical Institute Peshawar, Pakistan \\ ${ }^{2}$ Aga Khan University School of Nursing Karachi, Pakistan \\ ${ }^{3}$ Medical Officer, Pakistan
}

${ }^{4}$ Rehman College of Nursing, Rehman Medical Institute Peshawar, Pakistan

Received: September 15, 2017; Published: September 27, 2017

*Corresponding author: Muslim Shah, Assistant Professor, Rehman College of Nursing, Rehman Medical Institute Peshawar, Pakistan

\begin{abstract}
Nursing is feminized profession by its nature, and traditional development of its concept of caring to sick for centuries. Nursing is a profession established by women that support the stereotypical feminine image with qualities of nurturing, and caring, in contrast to malecharacteristics of power, aggression, and authority. Males have concerns related to stereotyping and role strains, particularly in relation to patient care, as patients expecting female nurses to care for them, which cause difficulty in adjustment for men in nursing profession. The purpose of this review is to explore the perceptions of male nurses about the nursing profession, and to identify the reasons for choosing nursing as a career, and to discover the barriers in practice, and factors that affecting male nurses practices. There is a need to explore the perceptions of registered male nurses about nursing profession, identify the barriers that men are facing, and to elaborate the feelings of satisfaction to choose nursing as a career.
\end{abstract}

Keywords : Nursing; Feminized Profession; Male Nursing; Career

\section{Introduction}

Nursing is feminized profession by its nature, and traditional development of its concept of caring to sick for centuries. Nursing has been stereotyped as a female dominated profession since the time of Florence Nightingale, worldwide [1,2]. Before the Crimean war, men had the responsibility to provide basic care to the wounded. However, from that war to the present, nursing profession began to be dominated by female [3]. Although the evolution of men into nursing profession has been increased over the past two decades, but still men constitute a small number of the nursing population. It is also noticed that women are moving into previously male dominated professions, such as medicine, law, and business, due to support provided to them to enter in men dominated professions. However, the movement of males into nursing profession is slow because of lack of attention and support given to them, to enter into female dominated profession [4]. Nursing is a profession established by a woman that supports the stereotypical feminine image with qualities of nurturing, and caring, in contrast to male characteristics of power, aggression, and authority [3]. Now the question is that, what happened when men enter in nursing profession? Choosing nursing as a career for men is likely to be colored by practical concerns, such as hand some salary, job security, chances of promotion, and family support [4]. Furthermore, Anthony argued that caring is the crucial element of nursing and men should demonstrate caring attitudes, as they are socialized to lack of visible expression of emotions as compared to women, who display caring behaviors and open expression of emotions. In a female dominant profession, being a male faces many problems, however, studies have shown significance advantages for men in nursing profession, because men have potentials of high tech specialties in nursing, such as intensive care, operation abilities, and physical strength, which increase the demand of male nurses in this profession [5].

\section{Purpose of Paper}

The purpose of this review is to explore the perceptions of male nurses about the nursing profession. Furthermore, to identify the reasons for choosing nursing as a career, and to discover the barriers in practice, and factors that affecting male nurses practices.

\section{Search Methods}

The search strategy involved four electronic data bases which are Science Direct, Pub Med, CINAHL and Google Scholar. Key words, which were used: male nurses, nursing profession, male nurse and nursing profession, and perception of male nurses about nursing profession. General to specific strategy was followed by refining from general to specific, and filtrated according to date and key terms. The search was conducted in light of key terms as general, 
from 2004 to 2013, and from 2010 to 2013. Fourteen articles were found relevant to my topic, in which I integrated eight literatures in the review.

\section{Review of Literature}

The influx of men in nursing profession has been increased throughout the world, but still men contain very little population among nurses.Canadian Nurses Association (2005) reported 5.6 percent of the nurses in Canada were men, while the Department of Health and Human Services Health Resources and Services Administration of United States (2004) reported, men comprise 5.8 percent of the registered nurses [6]. There are certain barriers for men while entering in nursing profession. Males have concerns related to stereotyping and role strains, particularly in relation to patient care, as patients expecting female nurses to care for them, which cause difficulty in adjustment for men in nursing profession [7]. Few studies have been conducted related to my research question, in which some have highlighted the perceptions of male nurses and student male nurses, to explore the difficulties for men in nursing profession.

In one of the studies, Wang et al. [5] explored the male student nurses perceptions of the nursing profession and their learning experiences in a baccalaureate nursing program in Changsha, China. They used phenomenological approach and methodological frame work to guide their study. The study participants were fifteen male nursing students of degree program, and male nurses who were recently graduated. In depth interviews were methodology for the collection of data from the participants. Software Nvivo 8.0 was used for data analysis and six themes emerged from the data. The findings of the study revealed that out of 15 participants only one chose nursing as a key profession, while fourteen were assigned in nursing program after failure to get admission in other disciplines. The majority of participants expressed studying nursing as no other option, failure, or an error.

They also felt that patients trust on doctors more than nurses, and patients prefer female nurses while giving care and medicine to them. The participants were uncomfortable with the nursing skills and tend these skills to be feminine, and fit for female to perform. The male nurses worked in hospital with nursing staff having low level of education and they believed that the level of nursing research and practice is also very low as compared to physicians. The male students were uncomfortable in class room because of small numbers and dissatisfied from teaching activities, due to without considering of their learning needs. They have sense of inferiority while facing the society, and felt embarrassed being as a nurse. Some were not interested in bedside nursing and had goals to achieve higher education, and to get management posts. This study is contextual and cannot be generalized because it was conducted in one university and the perceptions explored were from students and novice nurses.

In another study, Stott [8] reports the finding of the study that investigated the factors affecting both the academic and clinical performance of male nursing students at a regional Australian university. Descriptive, qualitative design was chosen for the study. The participants of the research were eight male nursing students of undergraduate program at university in Australia. In depth interviews and written narratives in form of diary were used for data collection, and methodology used for data analysis was thematic analysis. The results of the study revealed that male nursing students have certain problems in academic and clinical setting. Different themes were identified from interviews and narratives. The main theme emerged from the data is, sense of feeling of isolation of male students during their study, and they were in ambiguity to continue or switch off the nursing field. Few of the informants described that they felt embarrassed while performing certain skills in clinical area, as a male. Some were worried, whether it could be possible to fulfill nursing role as caring and role model. The participants also acknowledged that nursing is a caring profession and hence, it is strongly identified with being a female. The students explored the affect of traditional role and expectation of society from them as a male. In such stereotypical views, it would cause problems for them in their practical life. These comments are similar to the findings by Wang et al. [5] who reported the same queries raised by male nursing students.

There are certain limitations in the above both studies. First, both studies were conducted in one university only. Second, the studies explored the perceptions of undergraduatestudents and novice nurses. These cannot represent the true image of male nurses' perception about nursing profession, and hurdles which male nurses are experiencing and are facing in the real scenario. The generalization of both studies is limited to their specific universities. Despite of certain barriers, men are entering in the female dominant profession. Now the question is that, are men nurses satisfied with their choice of career? In their study, Twomey Meadus [6] explore, why men choose nursing profession, barriers experiencing in their practical life, and to identify the factors of male nurses' satisfaction. Descriptive study design was used to explore the opinions of sixty two registered nurses through survey. Data were collected using a self-reportquestionnaire developed by the authors.

No reliable instrument for examining men's careerchoice and barriers specific to nursing was used. The findings revealthat the common purposes of becoming a nurse were job security, career opportunities, and the salary. Only nine participants chose nursing because of caring profession. Common barriers expressed was, being a male in female dominant profession were: sexual stereotypes, female oriented profession, and lackof recruitment strategies. All respondents stated that there is lack of recruitment initiatives to consider nursing as a career of choice for men. This study has certain limitations, it cannot be generalized due to small sample size, and the study was conducted in only one province of the Canada. The questionnaire should be refined and re tested by using a large sample size. The authors also suggested that further qualitative investigation should be made to identify the career satisfaction among male nurses.

\section{Conclusion}

After reviewing the available literature, nursing profession is feminine in nature. Men constitute very small proportion of nurse's 
population. Since last two decades, male entrance to nursing profession has been increased, despite of challenges face by men in academic and practical settings. It is identified that nursing is not a major career of choice for men. The literature review helped me to identify the gaps. Most of the studies are qualitative, and focused only on male student nurses perceptions towards nursing profession. There is a need to explore the perceptions of registered male nurses about nursing profession, identify the barriers that men are facing, and to elaborate the feelings of satisfaction to choose nursing as a career. Therefore, an exploratory descriptive qualitative nursing design is felt appropriate to explore the issue.

\section{References}

1. Yang CI, Gau ML, Shiau SJ, Hu WH, Shih FJ (2004) Professional career development for male nurse. Journal of Advanced Nursing 48(6): 642650.

2. Saritass S, Karadag M, Yildirim D (2009) School for HealthSciences University Students'Opinions about Male Nurses. Journal of Professional Nursing 25(5): 279-284.
3. Meadus RJ (2000) Men in Nursing: Barriers to Recruitment. Nursing Forum 35(3): 5-12.

4. Anthony AS (2006) Tear down the barriers of gender bias. Men in Nursing p. 43-49.

5. Wang H, Li X, Hu X, Chen H, Gao Y, et al. (2011) Perceptions of nursing profession and learning experiences of male students in baccalaureate nursing program in Changsha, China. Nurse Education Today 31(2011): $36-42$.

6. Twomey JC, Meadus RJ (2008) Despite the Barriers Men Nurses are Safisfied with Career Choices. Canadian Journal of Career Development $7(1): 30-34$.

7. Stott A (2004) Issues in the socialisation process of the male student nurse: implications for retention in undergraduate nursing courses. Nurse Education Today 24(2): 91-97.

8. Stott A (2007) Exploring factors affecting attrition of male students from an undergraduate nursing course: A qualitative study. Nurse Education Today 27: 325-332.

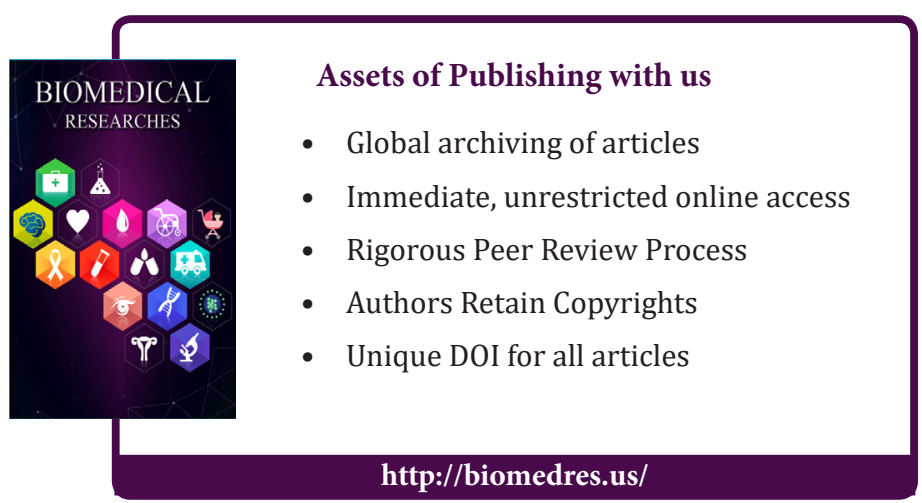

